\title{
Preparation and characterization of $\beta$-lactoglobulin hydrolysate-iron complexes
}

\author{
J. Zhou, ${ }^{*}$ X. Wang, ${ }^{*}$ T. Ai, ${ }^{*}$ X. Cheng, ${ }^{*}$ H. Y. Guo, ${ }^{*}$ G. X. Teng, $†$ and X. Y. Mao*1 \\ *Key Laboratory of Functional Dairy of Beijing and Ministry of Education, College of Food Science and Nutritional Engineering, \\ China Agricultural University, Beijing 100083, China \\ †Beijing Sanyuan Foods Co. Ltd., Beijing 102206, China
}

\section{ABSTRACT}

The purpose of this study was to determine the best preparation condition of $\beta$-lactoglobulin hydrolysateiron complexes and characterize its structural transformation both before and after binding using the UVvisible absorption spectrum, Fluorescence spectrum, and Fourier transform infrared spectroscopy. Results showed that $\beta$-lactoglobulin hydrolysates obtained with alcalase after hydrolysis for $6 \mathrm{~h}$ possessed the highest iron-binding capacity. The highest yield of complexes was obtained when the mass ratio between $\beta$-lactoglobulin hydrolysate and $\mathrm{Fe}^{3+}$ reached 40:1, with the optimal $\mathrm{pH}$ value of 7.0. All of the spectra indicated that some sites such as amido bonds transformed during chelation, and nitrogen atoms could chelate with $\mathrm{Fe}^{3+}$ to form coordinate bonds by offering electron pairs. Therefore, $\beta$-lactoglobulin hydrolysate-iron complexes may be good carriers for iron and possess great potential to be used as iron supplements.

Key words: $\beta$-lactoglobulin hydrolysate-iron complexes, iron-binding capacity, preparation condition, structural characterization

\section{INTRODUCTION}

Iron is an essential microelement that constitutes the spatial structure of hemoglobin, cytochromes, and many other key enzymes. It plays an important role in oxygen transport, cellular respiration, and energy metabolism regulation in organism (Gaucheron, 2000; Puig et al., 2005; Wang et al., 2007). Iron deficiency may lead to several dysfunctions such as iron deficiency anemia and reduce work efficiency by leaving you exhausted (Beard, 2001; Schumann et al., 2007). It is believed that iron deficiency has been a widespread nutrition problem nowadays. More than one-fourth of the

Received December 21, 2011

Accepted April 7, 2012.

${ }^{1}$ Corresponding author: maoxueying@cau.edu.cn population of the world is suffering from iron deficiency and it is particularly common among the aged, women, and teenagers (WHO, 2001).

Aimed to eliminate iron deficiency, different forms of iron supplements have been developed. Iron salts were first used in clinical treatment of iron deficiency anemia, but they caused a series of side effects including upset stomach and diarrhea with low bioavailability (Dewey et al., 2002; Hyder et al., 2002). Then, some security iron compounds such as heme iron, polyferose, and Ferrochel amino acid chelates were investigated for the production of iron-fortified food (Lebrun et al., 1998; Hurrell, 2002; London, 2004), but the relatively low bioavailability still prevents them from large-scale application. Recently, more and more researchers focus their attention on iron-peptide chelates, which are demonstrated to be an efficient iron supplement for human beings and animals without side effects. Peptides derived from milk (whey and casein), meat, and plasma protein have been proven to enhance iron uptake and increase its bioavailability (Chaud et al., 2002; Kim et al., 2007; Storcksdieck et al., 2007; Lee and Song, 2009).

Whey peptides, with potential functionalities including promoting iron absorption, have been widely studied over several years. Kim et al. (2007) have proven that alcalase had noticeable effectiveness in producing iron-binding peptides from whey protein concentrate. With prominently high lysine, alanine, and phenylalanine content, these peptides could be separated by ionexchange chromatography and reversed-phase HPLC. Sugiarto et al. (2009) measured the iron-binding constant of casein and whey protein isolate by Scatchard plots, and demonstrated that whey protein isolate had 8 binding sites for iron. However, few reports refer to the formation conditions of whey protein hydrolysateiron complexes and the structural transformation during the process of chelation.

The objective of this study was to determine the best preparation conditions of $\beta$-LG hydrolysate-iron complexes and characterize their structural transformation during the process of chelation. This can provide basic 
theories for the following function and activity evaluation of this potential iron supplement.

\section{MATERIALS AND METHODS}

\section{Materials and Reagents}

$\beta$-Lactoglobulin was obtained from Davisco Foods International Inc. (Eden Prairie, MN). Alcalase (EC 3.4.21.62, with an activity of 2.4 Anson units/g; endoproteinase from Bacillus licheniformis) and trypsin (EC 3.4.21.4, with an activity of $250 \mathrm{U} / \mathrm{mg}$ ) were provided by Novo Nordisk Biochem Inc. (Franklinton, NC). Neutrase (EC 3.4.21.14, endoproteinase from Bacillus subtilis, with a declared activity of $60,000 \mathrm{U} / \mathrm{g}$ ) was purchased from Aoboxing Biotech Co. Ltd. (Beijing, China). All of the chemicals were analytical grade, except potassium bromide was of Fourier transform infrared (FTIR) grade.

\section{Preparation of $\beta-L G$ Hydrolysates}

$\beta$-Lactoglobulin was dissolved in deionized water at substrate concentration of $5 \%$ (wt/vol). Then, the solutions were hydrolyzed with alcalase, Neutrase, or trypsin, respectively, under the following optimum conditions: for alcalase hydrolysis, the enzyme dose was $2.5 \%$ (wt/wt, defined as enzyme mass/substrate mass $\times 100 \%), \mathrm{pH}$ value was 8.0 , and temperature was $55^{\circ} \mathrm{C}$. For Neutrase hydrolysis, the enzyme dose was $2.5 \%, \mathrm{pH}$ value was 7.5 , and temperature was $50^{\circ} \mathrm{C}$. For trypsin hydrolysis, the enzyme dose was $2.5 \%, \mathrm{pH}$ value was 8.0 , and temperature was $37^{\circ} \mathrm{C}$. The hydrolysis process was carried out in a reactor equipped with a stirrer, $\mathrm{pH}$ electrode, and temperature controller. The $\mathrm{pH}$ value was kept constant, according to the requirements of each enzyme, with $1 \mathrm{M} \mathrm{NaOH}$ throughout the hydrolysis process. Samples were collected at periodic intervals $(0,1,2,3,4,5,6,7$, and $8 \mathrm{~h})$ and immediately heated in an $85^{\circ} \mathrm{C}$ water bath for $15 \mathrm{~min}$ to inactivate the proteases. After cooling to room temperature, the enzymatic hydrolysates were ultrafiltered with a 10,000Da molecular weight cut-off membrane (Sartorius Co., Göttingen, Germany) to remove the enzyme and nonhydrolyzed proteins. The permeate was collected and lyophilized.

\section{Degree of Hydrolysis}

The degree of hydrolysis (DH) of $\beta$-LG hydrolysates was calculated according to the method described by Mahmoud et al. (1992); $\mathrm{AN}_{\mathrm{h}}$ and $\mathrm{AN}_{\mathrm{c}}$ are the percent amino nitrogen of hydrolysate and intact $\beta-\mathrm{LG}$, respectively; TN refers to the mean percent total nitrogen of the intact $\beta$-LG solution and all hydrolysate samples; $\mathrm{P}_{\mathrm{f}}$ is a correction factor for side-chain nitrogen, which cannot be converted to amino nitrogen by hydrolysis of peptide bonds. The DH was calculated as follows:

$$
\mathrm{DH} \%=\frac{\mathrm{AN}_{\mathrm{h}}-\mathrm{AN}_{\mathrm{c}}}{\mathrm{TN} \times \mathrm{P}_{\mathrm{f}}} \times 100 .
$$

\section{Formation of $\beta$-LG Hydrolysate-Iron Complexes}

The freeze-dried $\beta$-LG hydrolysates with the best iron-binding capacity were mixed with ferric chloride at different mass ratios of hydrolysate mass:iron mass (0.1:1, 1:1, 10:1, 20:1, 25:1, 30:1, 35:1, 40:1, and 45:1). To determine the effect of $\mathrm{pH}$ on the iron-binding capacity, the reaction $\mathrm{pH}$ was maintained at 5.0, 5.5, 6.0, 6.5, 7.0, 7.5, and 8.0, respectively. The reaction was carried out in a shaker (DSHZ-300A; Taicang Experimental Instrument Co. Ltd., Jiangsu Province, China) at $25^{\circ} \mathrm{C}$. The unbound iron ions (i.e., free iron) were precipitated and removed by centrifugation at 3,000 $\times g$ for $20 \mathrm{~min}$ at $25^{\circ} \mathrm{C}$ after the binding process. The obtained $\beta$-LG hydrolysate-iron complexes in the supernatant were collected and lyophilized for the determination of ironbinding capacity and structural characterization.

\section{Determination of Iron-Binding Capacity}

The iron-binding capacity was determined according to the methods of Kim et al. (2007) and Lee and Song (2009). The iron content was measured using an atomic absorption spectrophotometer (AAS; WFX120B; Beijing Rayleigh Analytical Instrument Co. Ltd., Beijing, China). The iron-binding percentage could be calculated as follows:

$$
\begin{aligned}
& \text { Iron-binding capacity }(\%) \\
& =\frac{\text { iron content of supernant }(\mathrm{g})}{\text { total iron content of original solution }(\mathrm{g})} \times 100 \% \text {. }
\end{aligned}
$$

\section{Structural Transformation Characterization of $\beta-L G$ Hydrolysate-Iron Complexes}

$\boldsymbol{U V}$-Visible Spectra. The freeze-dried $\beta$-LG hydrolysate and its iron complex were dissolved in deionized water at a concentration of $1.0 \mathrm{mg} / \mathrm{mL}$, respectively. They were scanned over the wavelength range of 190 to $800 \mathrm{~nm}$, respectively, by a UV-visible spectrophotometer (UV-2600; UNICO Instrument Co. Ltd., Shanghai, China).

Fluorescence Spectra. The fluorescence spectra of $\beta$-LG hydrolysates $(10 \mathrm{mg} / \mathrm{mL})$, containing $0,0.2,0.4$, $0.6,0.8$, and $1.0 \mathrm{~m} M$ ferric chloride, were recorded over 
the emission wavelength ranging from 300 to $500 \mathrm{~nm}$ at an excitation wavelength of $280 \mathrm{~nm}$ by a fluorescence spectrometer (RF-5301PC; Shimadzu-GL Laboratory Supplies Co. Ltd., Shanghai, China).

FTIR Measurement. Two milligrams of $\beta-\mathrm{LG}$ hydrolysates or $\beta$-LG hydrolysate-iron complexes was mixed with dry $\mathrm{KBr}$, respectively. The mixture was ground into a fine powder and compressed into a thin disc. All spectra were recorded using an FTIR spectrophotometer (PerkinElmer Inc., Waltham, MA) over a wavenumber region between 4,000 and $400 \mathrm{~cm}^{-1}$ at a resolution of $4 \mathrm{~cm}^{-1}$ according to the method of van der Ven et al. (2002).

\section{Statistical Analysis}

All treatments in the present study were made in triplicate. Data were expressed as means \pm standard deviations and compared by one-way ANOVA at a significance level of $P<0.05$, using the SPSS package (SPSS 13.0 for Windows; SPSS Inc., Chicago, IL). A multiple-comparison procedure was also performed using Duncan's new multiple range test.

\section{RESULTS}

\section{Iron-Binding Capacity of $\beta$-LG Hydrolysates Prepared by Alcalase, Neutrase, and Trypsin for Different Periods}

The iron-binding capacity of $\beta$-LG hydrolysates prepared by trypsin (Figure 1A), Neutrase (Figure 1B), and alcalase (Figure 1C) for different periods was measured. Hydrolysates produced by alcalase showed the best iron-binding capacity, which was significantly higher than those of Neutrase and trypsin $(P<0.05)$. Hydrolysates obtained with trypsin showed an ironbinding capacity ranging from 24.40 to $35.78 \%$, which was significantly lower than that of the other 2 kind of proteinases $(P<0.05)$. Moreover, $\beta-\mathrm{LG}$ without enzymatic treatment exhibited the lowest iron-binding capacity of $18.73 \%$. The product obtained from 6-h hydrolysis with alcalase were used for further study because of the highest iron-binding capacity (70.93\%).

\section{Effects of Different Binding Conditions on Iron- Binding Capacity of $\beta-L G$ Hydrolysates Obtained with Alcalase at 6-h Hydrolysis}

To determine the optimum chelating mass ratio of $\beta$-LG hydrolysates to iron, the effects of different mass ratios of $0.1: 1,1: 1,10: 1,20: 1,25: 1,30: 1,35: 1,40: 1$, and 45:1 were measured. The iron-binding capacity increased markedly with the increase in mass ratio (Figure 2A). The highest iron-binding capacity was obtained when the mass ratio of $\beta-\mathrm{LG}$ hydrolysates to iron reached 40:1. A further increase in mass ratio (45:1) did not lead to significant enhancement in ironbinding capacity $(P>0.05)$.
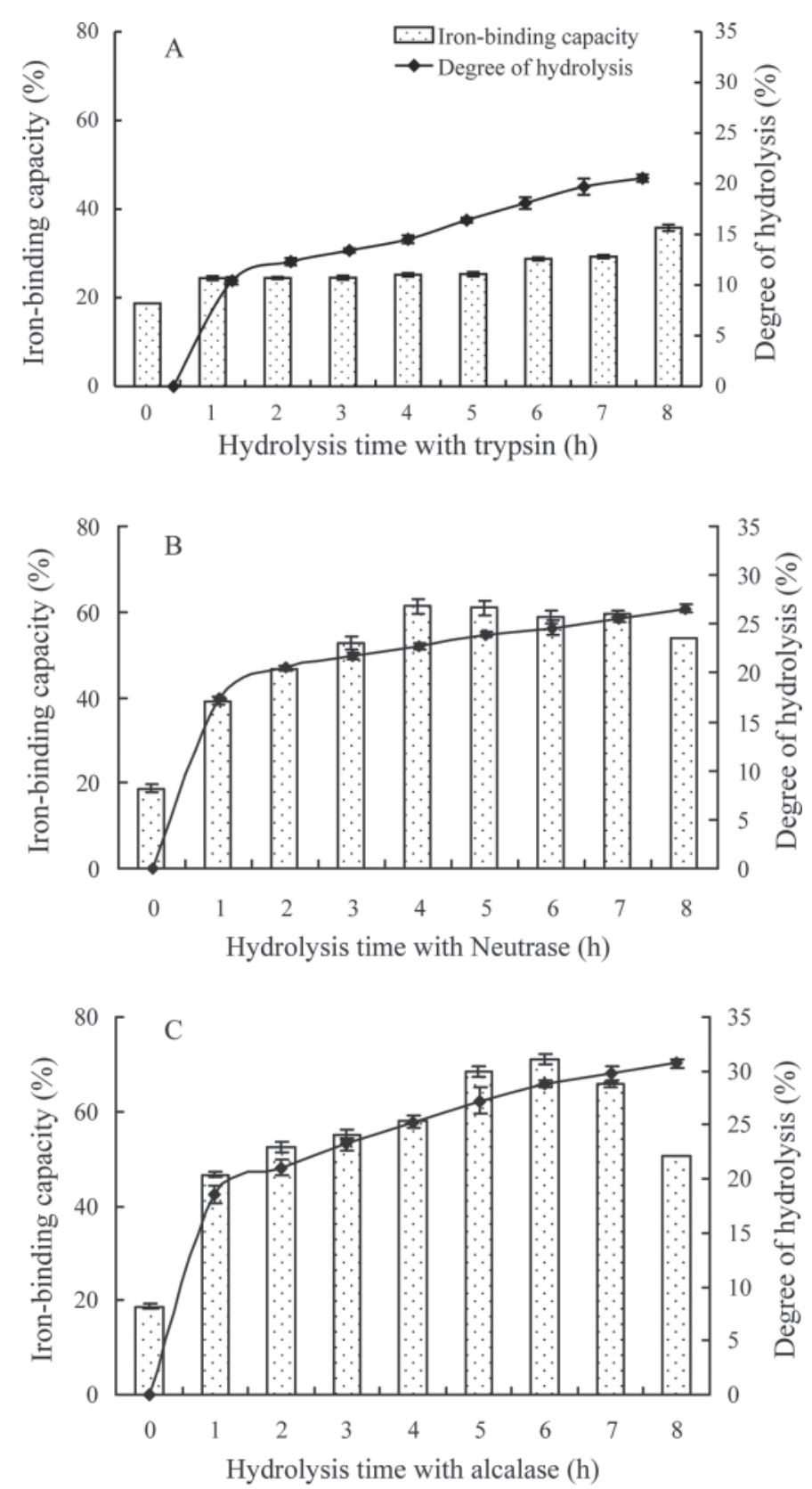

Figure 1. Effects of different hydrolysis time on the iron-binding capacity of $\beta$-LG hydrolysates prepared by trypsin (A), Neutrase (B), and alcalase $(\mathrm{C})$. All measurements are expressed as means $\pm \mathrm{SD}$ of 3 independent experiments. 


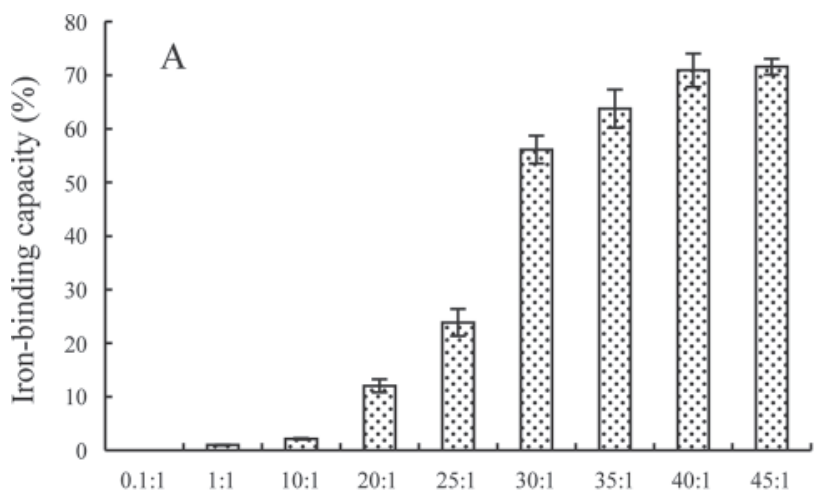

Mass ratio of $\beta$-lactoglobulin hydrolysates to iron

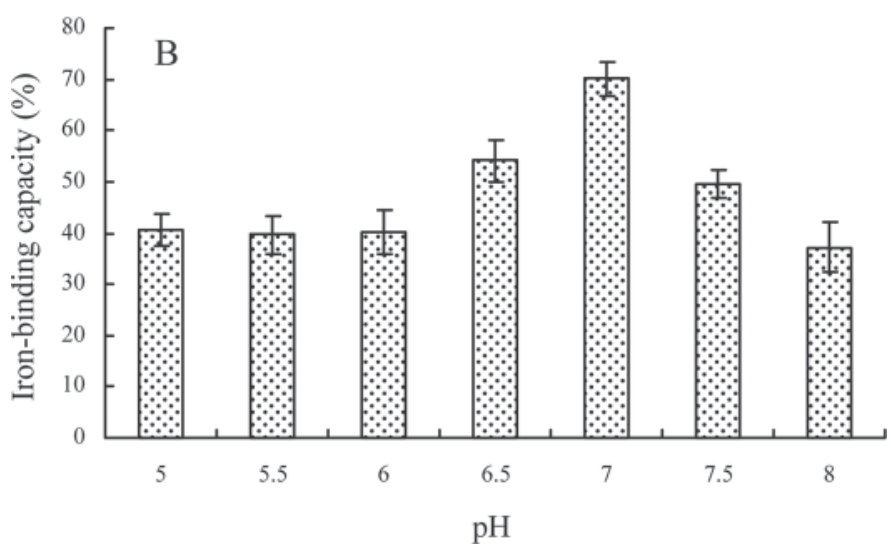

Figure 2. Effects of reaction $\mathrm{pH}(\mathrm{A})$, mass ratio between $\beta$-LG hydrolysates to iron (B) on the iron-binding capacity. All measurements were expressed as means \pm SD of 3 independent experiments.
The effect of various $\mathrm{pH}$ values of the reaction system on iron-binding capacity was analyzed by adjusting the $\mathrm{pH}$ to $5.0,5.5,6.0,6.5,7.0,7.5$, and 8.0, respectively. The results (Figure 2B) indicated that neutral or nearneutral $\mathrm{pH}$ (6.5 and 7.0) could promote the process of chelation, and the iron-binding capacity of hydrolysates decreased significantly when the $\mathrm{pH}$ increased or decreased out of the proper $\mathrm{pH}$ range $(P<0.05)$.

\section{UV-Visible Spectra of $\beta$-LG Hydrolysates and $\beta-L G$ Hydrolysate-Iron Complexes}

The UV-visible spectra of $\beta$-LG hydrolysates and $\beta$-LG hydrolysate-iron complexes show obvious differences and shifts (Figure 3). The maximum absorption peak of $\beta$-LG hydrolysate shifted from 204 to $196 \mathrm{~nm}$, whereas another absorption peak $(277 \mathrm{~nm})$ disappeared after chelation.

Fluorescence Spectra of $\beta-L G$ Hydrolysate and $\beta-L G$ Hydrolysate-Iron Complexes

To gain further information of structural transformation during chelation, $\beta-\mathrm{LG}$ hydrolysates containing different concentrations of iron were analyzed by a fluorescence spectrometer (Figure 4). The fluorescence intensity significantly dropped $(P<0.05)$ when the iron concentration $(0,0.2,0.4,0.6,0.8$, and $1.0 \mathrm{~m} M$ ferric chloride) of the mixture increased, and the absorption peak shifted from 359 to $370 \mathrm{~nm}$.

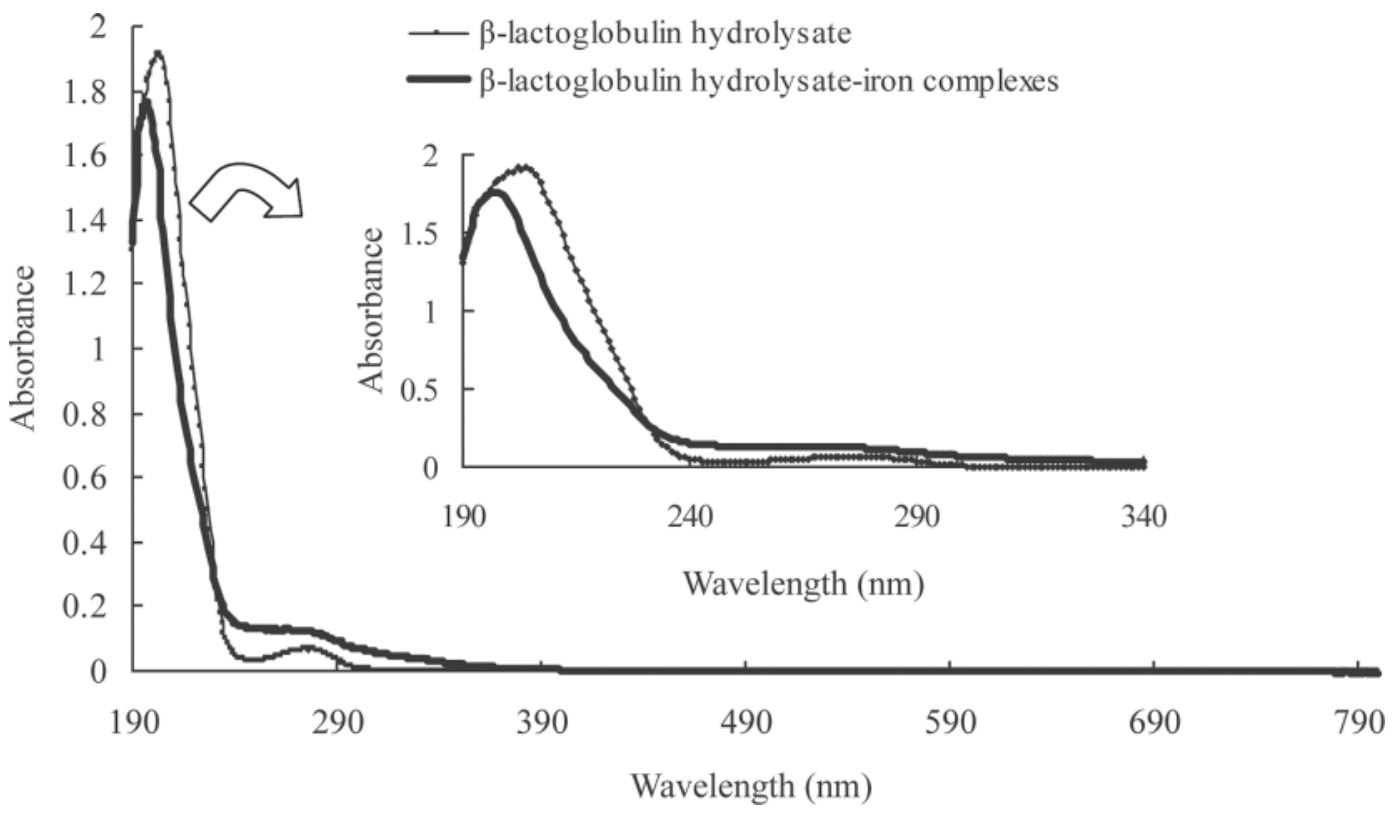

Figure 3. Ultraviolet-visible spectra of $\beta$-LG hydrolysates and $\beta$-LG hydrolysate-iron complexes over the wavelength range from 190 to 800 $\mathrm{nm}$. 
4234

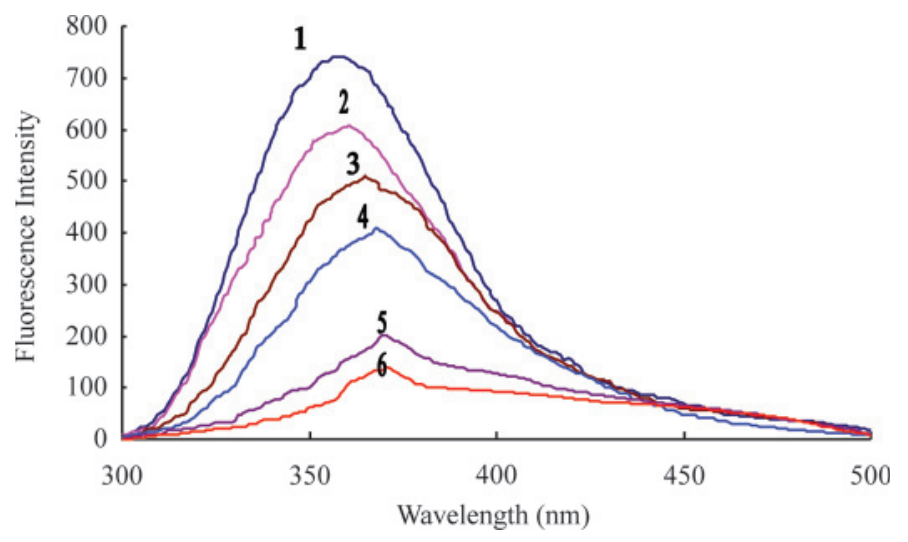

Figure 4. Fluorescence spectra of $\beta$-LG hydrolysates under different concentrations of iron. Numbers $1,2,3,4,5$, and 6 above the curve correspond to the spectra of $\beta$-LG hydrolysates containing $0,0.2,0.4$ $0.6,0.8$, and $1.0 \mathrm{~m} M$ ferric ions, respectively. Color version available in the online PDF.

\section{FTIR Spectra of $\beta-L G$ Hydrolysates and $\beta-L G$ Hydrolysate-Iron Complexes}

The FTIR spectra of $\beta$-LG hydrolysate and $\beta$-LG hydrolysate-iron complexes are shown in Figure 5. The absorption bands at 1,644 and $1,591 \mathrm{~cm}^{-1}$ (Figure 5B) in the spectra of $\beta$-LG hydrolysate corresponds to the vibration of amide I $(\mathrm{C}=\mathrm{O})$ and amide II $(\mathrm{N}-\mathrm{H}$ and C-N). After binding with $\mathrm{Fe}^{3+}$, the band corresponding to the amide I group is shifted from 1,644 to $1,651 \mathrm{~cm}^{-1}$ (Figure 5B) with weak intensity, caused primarily by the amide carbonyl $(\mathrm{C}=\mathrm{O})$ stretching vibration of peptide groups. Moreover, the band shifted from 3,408 to 3,375 $\mathrm{cm}^{-1}$ with lower intensity (Figure $5 \mathrm{~A}$ ), which can be attributed to N-H stretch and the hydrogen bonds were replaced by Fe-N bonds after chelation. The appearance of new bands at 1,086,1,181, and 1,253 $\mathrm{cm}^{-1}$ (Figure $5 \mathrm{~B})$, which can be attributed to the transformation of carboxylate groups and the formation of $\mathrm{C}-\mathrm{O}-\mathrm{Fe}$ bonds, appears in the spectrum of $\beta-\mathrm{LG}$ hydrolysate-iron complex. The appearance of new absorbance peaks at 521 and $546 \mathrm{~cm}^{-1}$ and the shifts of preexistant bands demonstrate that some bonds in $\beta$-LG hydrolysate can bind with iron and form complexes.

\section{DISCUSSION}

With a broader specificity for cleaving peptide bonds (Smyth and FitzGerald, 1998), alcalase is widely used in producing iron-binding peptides (Kim et al., 2007; Huang et al., 2011). The present study shows that the best iron-binding capacity appears after 6-h hydrolysis when the degree of hydrolysis of the obtained hydrolysate is $28.76 \%$. All of these may attribute to the suffi- cient exposure of iron-binding sites through hydrolysis. In addition, iron-binding capacity decreased when the binding sites were damaged, which was induced by excessive hydrolysis of $\beta$-LG.

To provide a good iron supplement, binding conditions of $\beta$-LG hydrolysate to iron were optimized in the present study. The iron-binding capacity increased significantly with the increase in mass ratio between hydrolysates and iron, until the optimum ratio (40:1) was reached, which probably meant that the binding sites were completely occupied by ferric ions. Therefore, extra increase of mass ratio over the optimum level hardly works on increasing iron-binding capacity (Wang et al., 2011a). Chelation pH also plays a key role during the binding process. Acidification will weaken the iron-binding capacity of hydrolysates, which is in agreement with Baumy and Brule (1988a) who found that the iron-binding capacity of $\beta$-LG decreased with the decrease in $\mathrm{pH}$ (from $\mathrm{pH} 6.6$ to 5.0). The present study demonstrated that neutral $\mathrm{pH}$ was suitable for the chelation. Formation of the complexes is certainly related to the electron-providing ability of the ligands. As the $\mathrm{pH}$ increases to above 7.0, possible chemical groups such as $\mathrm{COOH}, \mathrm{CONH}$, and $\mathrm{NH}_{2}$ will keep a negative charge, which make them tend to bind with ferric ions (Baumy and Brule, 1988b). The binding capacity decreased when the $\mathrm{pH}$ was higher than 7.0, which may due to lower solubility of $\mathrm{Fe}^{3+}$ (Miller and Berner, 1989). Therefore, a neutral pH (7.0) is more appropriate for the binding process than other $\mathrm{pH}$ conditions.

In the present study, the UV-visible spectra and fluorescence spectra showed that $\beta-L G$ hydrolysates did bind with iron and formed complexes. The maximum absorption peak of the UV-visible spectra of $\beta-\mathrm{LG}$ hydrolysate-iron complexes shifted from 204 to $196 \mathrm{~nm}$ after chelation, which probably means that the nitrogen atom of the amido bond was involved in the chelating procedure (Iwahashi, 2000; Anderson et al., 2004). The disappearance of absorption peak at $277 \mathrm{~nm}$ may be due to charge migration happened in tyrosine, tryptophan, and phenylalanine during the binding process with iron (Mach and Middangh, 1994). Endogenous fluorescence of tyrosine, tryptophan, and phenylalanine converged at $350 \mathrm{~nm}$ in the fluorescence spectra of $\beta$-LG hydrolysates, and decreased dramatically with the increase in iron concentration. These amino acids transfer to the surface of the molecule during chelation with iron, which leads to a red shift of the maximum absorption peak (Knappskog and Haavik, 1995; Miranda et al., 2005). A high concentration of iron may cause fluorescence quenching, which also makes a contribution to the decrease in the fluorescence intensity (Uppal et al., 2008). 

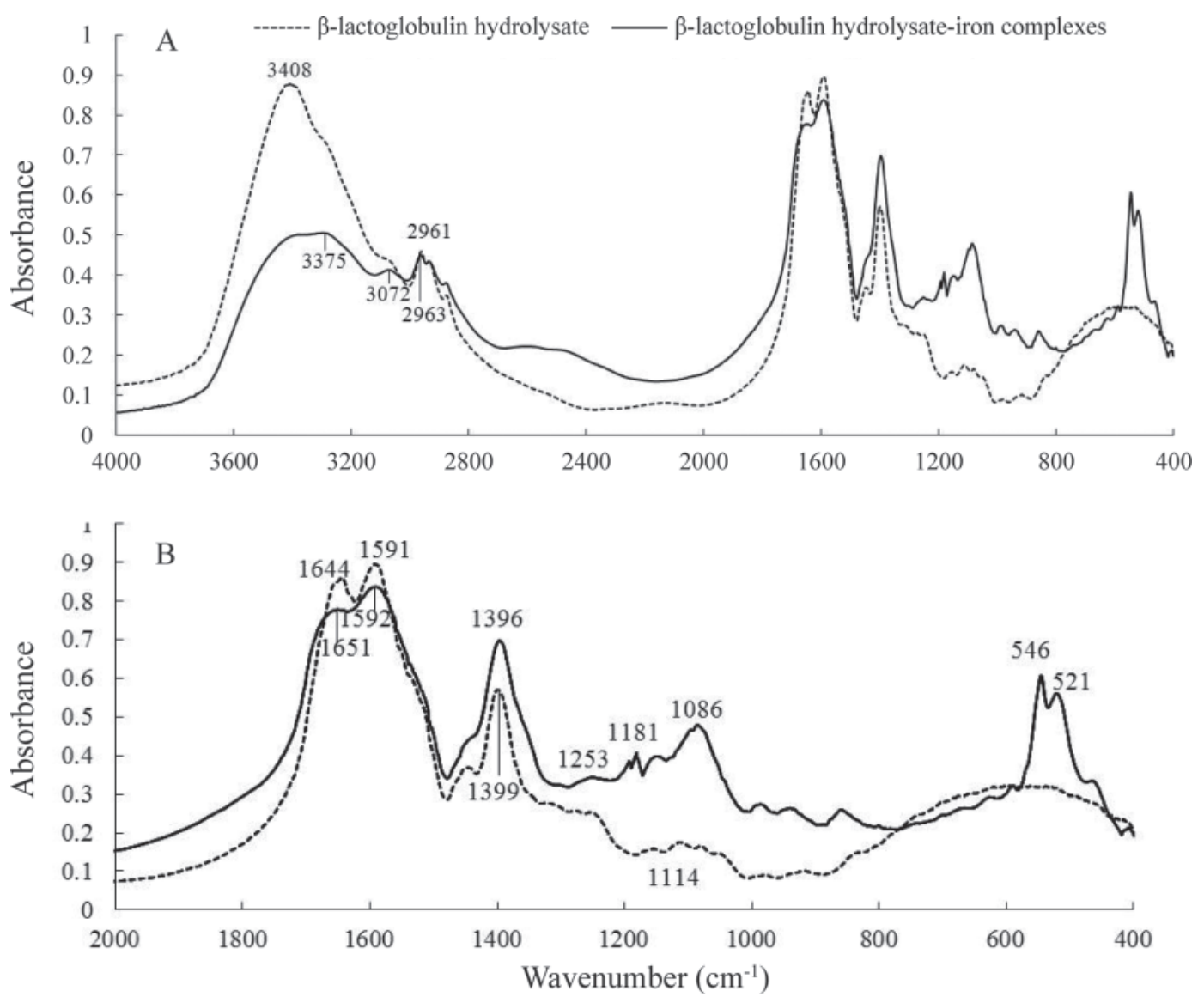

Figure 5. Fourier transform infrared (FTIR) spectra of $\beta$-LG hydrolysates and $\beta$-LG hydrolysate-iron complexes in the regions from 4,000 to $400 \mathrm{~cm}^{-1}$ (A) or regions from 2,000 to $400 \mathrm{~cm}^{-1}$ (B).

The FTIR spectra demonstrate that $\beta$-LG hydrolysates do bind with iron and form peptide-iron complexes, which are associated with their characteristic amide groups. The binding site for ferric ions mainly corresponds to the amide groups, due to $\mathrm{C}=\mathrm{O}$ stretching, C-N stretching, N-H stretching, and C-O bending. The appearance of strong bands at wavelengths of $1,086,1,181$, and $1,253 \mathrm{~cm}^{-1}$ indicates the coordination of the C-O-Fe bond in the peptide-iron complex. Chaud et al. (2002) also stated that ferric chloride could bind with casein enzymatic hydrolysates to form $\mathrm{Fe}^{3+}$-peptide complex, and the chief iron-binding site relates to the amide and carboxylate groups. Wang et al. (2011b) also found that the band related to the amide bond of FTIR spectra markedly shifted after chelation and contributed to the transformation of carboxylate groups and the formation of the C-O-Fe bond. The peak shifts from 3,408 to $3,375 \mathrm{~cm}^{-1}$, which corresponds to the replacement of hydrogen bonds by the Fe-N bond and could confirm the formation of complexes. The nitrogen atom could form coordinate bonds with 1 ferric ion by offering electron pairs (van der Ven et al., 2002).
Huang et al. (2011) drew a similar conclusion that the appearance of the stronger bond at $1,050 \mathrm{~cm}^{-1}$ should be attributed to $\mathrm{C}-\mathrm{O}-\mathrm{Fe}$, and the hydrogen bonds were replaced by $\mathrm{Fe}-\mathrm{N}$ bonds after chelation. The component at $1,651 \mathrm{~cm}^{-1}$, contributing to the amide I band area, has been assigned to the $\alpha$-helix in the complex (Stuart, 2004). Thus, binding between iron and $\beta-L G$ hydrolysate may produce a significant amount of $\alpha$-helix in the complex. Further research on the structural transformation is required to identify more details during the chelation process. To evaluate the effects of the obtained $\beta$-LG hydrolysate-iron complexes in preventing iron deficiency, further investigation is still needed.

\section{CONCLUSIONS}

The $\beta$-LG hydrolysates obtained with alcalase for 6-h hydrolysis exhibit the highest iron-binding capacity. Compared with $\beta$-LG hydrolysates, the complexes chelated between the hydrolysates and iron salts transformed significantly in spectroscopy, which indicates that noticeable structural transformation happened 
during the binding process. Several chemical bonds, such as amido bonds, are involved in the chelation and tend to form a C-O-Fe bond, reflected as new absorption peaks in FTIR spectroscopy.

\section{ACKNOWLEDGMENTS}

We are grateful for the financial support of this work by the National Natural Science Foundation of China (Beijing, China; grant no. 30972291) and Beijing Natural Science Foundation (Beijing, China; grant no. 5102021).

\section{REFERENCES}

Anderson, R. J., D. J. Bendell, and P. W. Groundwater. 2004. Ultraviolet-visible (UV-Vis) spectroscopy. Pages 7-23 in Organic Spectroscopic Analysis. The Royal Society of Chemistry, Cambridge, UK.

Baumy, J. J., and G. Brule. 1988a. Binding of bivalent cations to $\alpha$-lactalbumin and $\beta$-lactoglobulin: Effect of $\mathrm{pH}$ and ionic strength. Lait 68:33-48.

Baumy, J. J., and G. Brule. 1988b. Effects of $\mathrm{pH}$ and ionic strength on the binding of bivalent cations to $\beta$-casein. Lait 68:409-417.

Beard, J. L. 2001. Iron biology in immune function, muscle metabolism and neuronal functioning. J. Nutr. 131:568S-580S.

Chaud, M. V., C. Izumi, Z. Nahaal, T. Shuhama, M. de Lourdes Pires Bianchi, and O. de Freitas. 2002. Iron derivatives from casein hydrolysates as a potential source in the treatment of iron deficiency. J. Agric. Food Chem. 50:871-877.

Dewey, K. G., M. Domellöf, R. J. Cohen, L. L. Rivera, O. Hernell, and B. Lönnerdal. 2002. Iron supplementation affects growth and morbidity of breast-fed infants: Results of a randomized trial in Sweden and Honduras. J. Nutr. 132:3249-3255.

Gaucheron, F. 2000. Iron fortification in dairy industry. Trends Food Sci. Technol. 11:403-409.

Huang, G., Z. Ren, and J. Jiang. 2011. Separation of iron-binding peptides from shrimp processing by-products hydrolysates. Food Bioprocess Technol. 4:1527-1532.

Hurrell, R. 2002. How to ensure adequate iron absorption from ironfortified food. Nutr. Rev. 60:S7-S15.

Hyder, S. M., L. A. Persson, A. M. Chowdhury, and E. C. Ekström. 2002. Do side-effects reduce compliance to iron supplementation? A study of daily and weekly-dose regimens in pregnancy. J. Health Popul. Nutr. 20:175-179.

Iwahashi, H. 2000. Some polyphenols inhibit the formation of pentyl radical and octanoic acid radical in the reaction mixture of linoleic acid hydroperoxide with ferrous ions. Biochem. J. 346:265-273.

Kim, S. B., I. S. Seo, M. A. Khan, K. S. Ki, M. S. Nam, and H. S. Kim. 2007. Separation of iron-binding protein from whey through enzymatic hydrolysis. Int. Dairy J. 17:625-631.

Knappskog, P. M., and J. Haavik. 1995. Tryptophan fluorescence of human phenylalanine-hydroxylase produced in Escherichia coli. Biochemistry 34:11790-11799.

Lebrun, F., A. Bazus, and D. Guillochon. 1998. Solubility of heme in heme-iron enriched bovine hemoglobin hydrolysates. J. Agric. Food Chem. 46:5017-5025.
Lee, S.-H., and K. B. Song. 2009. Purification of an iron-binding nonapeptide from hydrolysates of porcine blood plasma protein. Process Biochem. 44:378-381.

London, E. 2004. The molecular formula and proposed structure of the iron-dextrin complex, Imferon. J. Pharm. Sci. 939:1838-1846.

Mach, H., and C. R. Middaugh. 1994. Simultaneous monitoring of the environment of tryptophan, tyrosine and phenylalanine residues in proteins by near-ultra-violet second-derivative spectroscopy. Anal. Biochem. 222:323-331.

Mahmoud, M. I., W. T. Malone, and C. T. Cordle. 1992. Enzymatic hydrolysis of casein: Effect of degree of hydrolysis on antigenicity and physical properties. J. Food Sci. 57:1223-1229.

Miller, D. D., and L. A. Berner. 1989. Is solubility in vitro a reliable predictor of iron bioavailability? Biol. Trace Elem. Res. 19:11-24.

Miranda, F. F., M. Kolberg, K. K. Andersson, C. F. G. C. Geraldes, and A. Martínez. 2005. The active site residue tyrosine 325 influences iron binding and coupling efficiency in human phenylalanine hydroxylase. J. Inorg. Biochem. 99:1320-1328.

Puig, S., E. Askeland, and D. J. Thiele. 2005. Coordinated remodeling of cellular metabolism during iron deficiency through targeted mRNA degradation. Cell 120:99-110.

Schümann, K., T. Ettle, B. Szegner, B. Elsenhans, and N. W. Solomons. 2007. On risks and benefits of iron supplementation recommendations for iron intake revisited. J. Trace Elem. Med. Biol. $21: 147-168$.

Smyth, M., and R. J. FitzGerald. 1998. Relationship between some characteristics of WPC hydrolysates and the enzyme complement in commercially available proteinase preparations. Int. Dairy J. 8:819-827.

Storcksdieck, S., G. Bonsmann, and R. F. Hurrell. 2007. Iron-binding properties, amino acid composition, and structure of muscle tissue peptides from in vitro digestion of different meat sources. J. Food Sci. 72:S19-S29.

Stuart, B. 2004. Infrared Spectroscopy: Fundamentals and Applications. John Wiley \& Sons Ltd., Chichester, UK.

Sugiarto, M., A. Ye, and H. Singh. 2009. Characterisation of binding of iron to sodium caseinate and whey protein isolate. Food Chem. 114:1007-1013.

Uppal, R., K. V. Lakshmi, and A. M. Valentine. 2008. Isolation and characterization of the iron-binding properties of a primitive monolobal transferrin from Ciona intestinalis. J. Biol. Inorg. Chem. 13:873-885.

van der Ven, C., S. Muresan, H. Gruppen, D. B. A. de Bont, K. B. Merck, and A. G. J. Voragen. 2002. FTIR spectra of whey and casein hydrolysates in relation to their functional properties. J. Agric. Food Chem. 50:6943-6950.

Wang, W., X. Di, R. B. D'Agostino Jr., S. V. Torti, and F. M. Torti 2007. Excess capacity of the iron regulatory protein system. J. Biol. Chem. 282:24650-24659.

Wang, X., M. Li, M. Li, X. Y. Mao, J. Zhou, and F. Z. Ren. 2011a Preparation and characteristics of yak casein hydrolysate-iron complex. Int. J. Food Sci. Technol. 46:1705-1710.

Wang, X., J. Zhou, P. S. Tong, and X. Y. Mao. 2011b. Zinc-binding capacity of yak casein hydrolysate and the zinc-releasing characteristics of casein hydrolysate-zinc complexes. J. Dairy Sci. 94:2731-2740.

WHO (World Health Organization). 2001. Iron Deficiency Anemia: Assessment, Prevention, and Control. Pages 1-22. WHO, Geneva Switzerland. 